\title{
Rheumatoid factor and anticitrullinated protein antibodies in rheumatoid arthritis: diagnostic value, associations with radiological progression rate, and extra-articular manifestations
}

\author{
L De Rycke, I Peene, I E A Hoffman, E Kruithof, A Union, L Meheus, K Lebeer, B Wyns, C Vincent, \\ H Mielants, L Boullart, G Serre, E M Veys, F De Keyser
}

Ann Rheum Dis 2004;63:1587-1593. doi: 10.1136/ard.2003.017574

See end of article for authors' affiliations

Correspondence to: Dr L De Rycke, Department of Rheumatology, Ghent University Hospital, De Pintelaan 185, 9000 Ghent, Belgium;

leen.derycke@ugent.be

Accepted 27 January 2004

\begin{abstract}
Background: Autoantibodies such as rheumatoid factor (RF) and anticitrullinated protein antibodies can be detected in rheumatoid arthritis (RA) sera.

Objective: To determine the diagnostic values of RF, anticitrullinated protein antibodies, and the shared epitope (SE), and their associations with radiological progression rates and extra-articular manifestations. Methods: Population 1 consisted of sera from 315 patients, consecutively sent for detection of anticitrullinated protein antibodies, of which 264 were used to determine the sensitivity and specificity of RF and of antibodies against three synthetic citrullinated peptides: peptide $A$ (pepA), peptide $B($ pepB), and CCP2. Population 2 consisted of sera from 180 longstanding RA patients and was used to determine associations of RA associated antibodies and the SE with radiological progression rates and extraarticular manifestations. Antibodies to pepA and pepB were detected by line immunoassay, and antibodies to CCP2 by ELISA. HLA Class II typing was performed by LiPA.

Results: In population 1, we defined adapted cut offs corresponding to a specificity of $\geqslant 98.5 \%$. This yielded the following sensitivities: RF 12.8\%; anti-pepA antibodies $63.6 \%$; anti-pepB antibodies $54.2 \%$; and anti-CCP2 antibodies $73.7 \%$. In population 2, significant differences in radiological progression rates were found between positive and negative patients for different RA antibodies and the SE. RF, but not anticitrullinated protein antibodies or the $\mathrm{SE}$, were more frequent in patients with extra-articular manifestations.

Conclusion: A valid comparison of RA associated antibodies shows superior sensitivity of the anticitrullinated protein antibodies compared with RF. The presence of RA associated antibodies and the SE are indicative for poorer radiological outcome, and presence of extra-articular manifestations is associated with RF but not with anticitrullinated protein antibodies.
\end{abstract}

$\mathrm{R}$ heumatoid arthritis (RA) is a chronic inflammatory disease in which the peripheral joints are the primary sites of inflammation, often leading to destruction of these joints. Extra-articular manifestations (vasculitis, rheumatoid nodules) occur, especially in patients with longstanding RA. Although the precise aetiology of the disease remains elusive, there is strong evidence for autoimmunity, as several autoantibodies are associated with RA. Rheumatoid factor (RF) is detected in the majority of patients with established disease, and constitutes one of the American College of Rheumatology (ACR) classification criteria. ${ }^{1}$ Another group of autoantibodies, including antiperinuclear factor, antikeratin antibodies, and antifilaggrin antibodies, was later shown to be more specific for RA. ${ }^{2-5}$ This group of antibodies targets epitopes in which arginine is converted by peptidylarginine deiminase into citrulline during a post-translational modification..$^{6-8}$ Therefore, this group of RA associated autoantibodies can be referred to as anticitrullinated protein antibodies. These antibodies can also be detected by more recently developed serological tests using synthetic citrullinated substrates. ${ }^{5-7}$ One of these tests constitutes of an ELISA with a single cyclic citrullinated peptide (CCP) that has a three dimensional structure optimally recognised by the corresponding RA autoantibodies (anti-CCPl antibodies). ${ }^{9}{ }^{10}$ A second generation anti-CCP ELISA claiming higher sensitivity and specificity due to optimalisation of the substrate is now also available. ${ }^{11}{ }^{12}$ Based on the results of epitope mapping of human natural filaggrin, molecular modelling, and computational chemistry, two synthetic citrullinated peptides (peptide A (pepA) and peptide B (pepB)) have been developed and are used in a line immunoassay based test. ${ }^{6}$ All these assays for the detection of anticitrullinated antibodies claim to be very specific with a fairly high sensitivity..$^{6}{ }^{9-12}$

Genetic studies have demonstrated that class II region genes, in particular HLA-DR-Bl alleles, appear to have a strong association with the disease. Multiple HLA-DR-Bl alleles encoding a conserved sequence at aminoacid positions 70-74 are associated with susceptibility and severity of RA. This conserved sequence is commonly known as the shared epitope (SE). The role of the SE in the evolution of articular destruction has yielded conflicting results; however, in most studies the presence of the SE is associated with increased joint destruction. ${ }^{13-15}$

Radiographs of hands and feet are used to assess the structural damage in RA. Evidence shows that the radiographic progression occurs at a constant rate in the natural course of RA. ${ }^{16-18}$ As this radiological damage is considered to

Abbreviations: $A C R$, American College of Rheumatology; CCP, cyclic citrullinated peptide; RA, rheumatoid arthritis; RF, rheumatoid factor; $R O C$, receiver operating characteristic; $S E$, shared epitope 
be largely irreversible, especially outside the context of biological treatments, it represents a cumulative process of joint destruction over time. The availability of early, specific prognostic markers for RA is becoming increasingly important, as adequate therapy can halt the structural damage. ${ }^{19} 20$

The aims of the present study were: $(a)$ to compare the sensitivity and specificity of RF and antibodies to three different synthetic citrullinated peptides (pepA, pepB, and CCP2) for the detection of RA; $(b)$ to investigate whether these autoantibodies and the SE are associated with the radiological progression rates in patients with established RA; (c) to evaluate whether the SE has an added value to the autoantibodies in the identification of patients with RA and higher radiological progression rates; and $(d)$ to analyse the association of extra-articular manifestations (rheumatoid nodules and vasculitis) with autoantibodies and the SE.

\section{PATIENTS AND METHODS}

\section{Study population 1}

In order to determine the diagnostic value of different RA associated autoantibodies, sera of 315 patients with rheumatic inflammatory symptoms, seen at a non-academic rheumatology department (Elisabeth Hospital, SijseleDamme, Belgium), were consecutively sent to our laboratory for the detection of antibodies to citrullinated peptides. The blood samples were obtained in the context of a diagnostic investigation. Upon further follow up of this consecutive cohort, patients were classified as having RA if they were diagnosed with RA by the clinician and fulfilled the revised ACR criteria ${ }^{1}$; a total of 118 patients (male to female ratio 41:77, median age 63.5 years (range 30 to 84 ), median disease duration 5.0 years (range 0.12 to 44 )). There were 146 patients (male to female ratio 39:107, mean age 53.2 years (range 17-82)) diagnosed with a disease other than RA, designated as non-RA (osteoarthritis $\mathrm{n}=25$; polymyalgia rheumatica $\mathrm{n}=25$; systemic lupus erythematosus $\mathrm{n}=17$; spondyloarthropathy $\mathrm{n}=9$, others $\mathrm{n}=70$ ). The other 51 patients remained with uncertain diagnoses and were therefore not considered for further analysis.

\section{Study population 2}

To evaluate the association between RA associated antibodies and the radiological progression rate, 180 consecutive patients diagnosed with RA and fulfilling the revised ACR criteria, ${ }^{1}$ who had a disease duration of at least 4 years, were followed at three Belgian rheumatology departments (University Hospital, Ghent; Elisabeth Hospital, SijseleDamme; and St Augustinus Hospital, Antwerp). None of the patients from population 1 was included in population 2 . For each patient, we obtained blood samples and the following patient information: age, sex, ethnic origin, disease duration, and the presence of extra-articular manifestations (vasculitis or rheumatoid nodules) at any time during the evolution of disease. The male to female ratio was 51:129, median age was 62.6 years (range 30 to 80 ) and the median disease duration was 9.0 years (range 4 to 39). All patients were white. Joint damage progression, further designated as "radiological progression rate" was defined as the modified Larsen score divided by the disease duration in years. Radiographs were taken at the time of blood sampling, unless they had been taken within a period of $<6$ months before inclusion. The Larsen score was determined on hand and foot $x$ rays (scores between 0 and 160). The $x$ rays were analysed by two independent readers blinded to the clinical and laboratory data. All patients were treated with classical disease modifying antirheumatic drugs such as methotrexate, gold salts, or sulfasalazine. None of the patients had received anti-TNF $\alpha$ treatment, other biologicals, or leflunomide. Oral informed consent was obtained.

\section{Rheumatoid factor}

For the detection of RF, an agglutination test using particles sensitised with human IgG was performed according to the manufacturer's instructions (Difco Laboratories, Detroit, MI, USA). Titres were converted to $\mathrm{U} / \mathrm{ml}$ using a reference serum-to correct for interassay variation, and a sample was considered positive if $\mathrm{RF} \geqslant 3.125 \mathrm{U} / \mathrm{ml}$, further designated as the "standard" cut off.

\section{Antipeptide $A$ and antipeptide $B$ antibodies}

Anti-pepA and anti-pepB antibodies were detected by a line immunoassay spotted with two peptides containing citrulline as described previously (prototype of INNO-LIA ${ }^{\mathrm{TM}}$ RA; Innogenetics, Ghent, Belgium). ${ }^{6}$ The assay was performed according to the manufacturer's instructions. Serum samples were considered positive for anti-pepA and/or anti-pepB antibodies if the visually read intensity was greater than or equal to the cutoff intensity. Additionaly, in study population 2, the strips were also scanned using a HP Scanjet 5P scanner.

\section{Anticitrullinated cyclic peptide antibodies}

Anti-CCP2 antibodies were detected by a commercially available ELISA containing synthetic peptides (Immunoscan RA, mark 2; Eurodiagnostica, Arnhem, The Netherlands). The ELISA was performed according to the manufacturer's instructions. Serum samples with a test result $>25 \mathrm{U} / \mathrm{ml}$ were considered positive, further designated as the "standard" cut off.

\section{HLA typing by line probe assay technology}

DNA was extracted from whole blood samples and amplified using INNO-LiPA HLA-DRB or HLA-DRBl decoder amplification kits (Innogenetics, Ghent, Belgium) as instructed by the manufacturer. The aminoacid sequences QRRAA, QKRAA, and RRAAA at positions 70-74 were considered to encode the SE sequence. For our analysis, we categorised each patient into one of three groups according to the presence of 0,1 , or 2 copies of the SE.

\section{Statistical analysis}

The statistical analyses were performed using SPSS 10.0. The sensitivities and specificities were calculated together with the $95 \%$ confidence interval (CI). A receiver operating characteristics (ROC) curve was generated by plotting sensitivity (y axis) against specificity ( $\mathrm{x}$ axis). Sensitivities were compared using McNemar testing. Correlation was sought using Spearman's $\rho$ correlation coefficients $\left(r_{s}\right)$. In order to compare subgroups of RA patients who were positive or negative for the RA antibodies or the SE, Student's $t$ test or Mann-Whitney $U$ test, respectively, were used, and $\mathrm{p}<0.05$ considered significant.

As an alternative, a different "clustering technique" was used to deduce the importance of combinations of parameters with respect to the radiological progression rate. Only three discrete parameters were considered for this clustering technique: RF (cut off $\geqslant 150 \mathrm{U} / \mathrm{ml}$ ), anti-CCP2 antibodies (cut off $\geqslant 42 \mathrm{U} / \mathrm{ml}$; representative for anticitrullinated protein antibodies), and the SE. Each parameter was scored as being either present or absent. The entire dataset contained 170 patients who were tested for all three parameters, and eight distinct combinations could be formed. Each combination had to contain at least 10 patients for generating a prediction.

\section{RESULTS}

Diagnostic value of RF and three assays to detect anticitrullinated protein antibodies in study population 1

Applying the standard cut offs, the sensitivities and specificities for the detection of RA, and the $95 \%$ confidence 
Table 1 Sensitivities and specificities according to the standard and adapted cut offs for RF and three anticitrullinated protein antibodies and the $95 \%$ confidence intervals as defined in study population 1

\begin{tabular}{lll}
\hline Test (cut off) & Sensitivity & Specificity \\
\hline Standard cut off & & \\
RF ( $\geqslant 3.125 \mathrm{U} / \mathrm{ml})$ & $78.6(71.2$ to 86.0$)$ & $80.8(74.4$ to 87.2$)$ \\
Anti-pepA antibodies & $63.6(54.9$ to 72.3$)$ & $100(98.0$ to 100$)$ \\
Anti-pepB antibodies & $54.2(45.3$ to 63.1$)$ & $99.3(96.8$ to 100$)$ \\
Anti-CCP2 antibodies & $75.4(67.6$ to 83.2$)$ & $97.3(93.8$ to 99.1$)$ \\
( $>25 \mathrm{U} / \mathrm{ml})$ & & \\
Adapted cut off & & \\
RF ( $\geqslant 150 \mathrm{U} / \mathrm{ml})$ & $12.8(6.7$ to 18.9$)$ & $98.6(95.8$ to 99.8$)$ \\
Anti-pepA antibodies & $63.6(54.9$ to 72.3$)$ & $100(98.0$ to 100$)$ \\
Anti-pepB antibodies & $54.2(45.3$ to 63.1$)$ & $99.3(96.8$ to 100$)$ \\
Anti-CCP2 antibodies & $73.7(65.8$ to 81.6$)$ & $98.6(95.8$ to 99.8$)$ \\
( $\geqslant 42 \mathrm{U} / \mathrm{ml})$ & & \\
\hline Values are given as $95 \%$ confidence interval. & \\
\hline
\end{tabular}

intervals of the different RA associated antibodies are given in table 1 . As described in the table, anti-pepA and anti-pepB antibodies reached very high specificities: for anti-pepA, a specificity of $100 \%$ and sensitivity of $63.6 \%$, and for antipepB, a specificity of $99.3 \%$ and sensitivity of $54.2 \%$. In order to compare the sensitivities of the different RA associated antibodies, ROC curve analysis was performed and revealed the following "adapted" cut offs, corresponding to a specificity level of at least $98.5 \%$ : RF $\geqslant 150 \mathrm{U} / \mathrm{ml}$ and antiCCP2 antibodies $\geqslant 42 \mathrm{U} / \mathrm{ml}$. The sensitivities and specificities of the different serological parameters when applying the adapted cut offs, and their $95 \%$ confidence intervals, are summarised in table 1 . At this high specificity level, the anticitrullinated protein antibodies yielded a statistically significant higher sensitivity compared with RF, which decreased to $12.8 \%(\mathrm{p}<0.001)$.

\section{Diagnostic value of combinations of RA associated autoantibodies in study population 1}

Subsequently, we evaluated whether combining tests could upgrade the sensitivities for RA without lowering the specificity below $98.5 \%$. Only two combinations of assays for the detection of anticitrullinated protein antibodies maintained the intended specificity level of at least $98.5 \%$. Positivity for anti-pepA or anti-pepB antibodies yielded a sensitivity of $65.3 \%$ and a specificity of $99.3 \%$. Positivity for anti-pepA or anti-CCP2 antibodies reached a sensitivity of $75.4 \%$ and specificity of $98.6 \%$; however, the sensitivity of this combination was not significantly higher than the sensitivity of the anti-CCP2 assay alone $(\mathrm{p}=0.5)$. As can be seen in table $2,75.4 \%$ of the patients with RA in study population 1 showed reactivity against at least one of the citrullinated peptides. Moreover, the simultaneous presence of antibodies to two or three citrullinated peptides yielded specificities of $100 \%$. All patients with RA and with only a single positive test (10.2\%) revealed anti-CCP2 antibodies. There was no significant improvement in sensitivity when combining the RF with one or more assays for the detection of anticitrullinated protein antibodies. One combination (positivity for RF or anti-pepA antibodies) maintained a specificity of $\geqslant 98.5 \%$ with a sensitivity of $65.3 \%$.

\section{Sensitivities of RF and anticitrullinated protein antibodies in study population 2}

The sensitivities of the anticitrullinated protein antibodies in the longstanding RA population (study population 2) were comparable with the sensitivities in study population 1 .
In study population 2, the following sensitivities were reached: RF, $24.6 \%$ (95\% CI 18.3 to $30.9 \%$ ); anti-pepA, $57.8 \%$ (95\% CI 50.6 to $65.0 \%$ ); anti-pepB, $55.0 \%$ (95\% CI 47.7 to $62.3 \%$ ); and anti-CCP2, $65.7 \%$ (95\% CI 58.7 to $72.7 \%$ ). Again, a significant difference in sensitivity was observed between RF and anticitrullinated protein antibodies $(\mathrm{p}<0.001)$.

\section{Relation of RF, anticitrullinated protein antibodies, and the SE with the radiological progression rate in study population 2}

Radiological progression rates were expressed in Larsen units corrected for disease duration in years. Applying the adapted cut offs as defined in study population 1 revealed statistically significant differences in the mean radiological progression rates between the antibody positive and antibody negative groups in study population 2 (RF, $\mathrm{p}=0.043$; anti-pepA, $\mathrm{p}=0.024 ;$ anti-pepB, $\mathrm{p}=0.008$; and anti-CCP2, $\mathrm{p}<0.001$ ) (fig 1).

The presence of the SE (single or double gene carriage of the SE) resulted in a significantly higher radiological progression rate (median $3.65 \vee 2.14, \mathrm{p}=0.009$ ) compared with the absence of the SE. With regard to a possible gene dosage effect, both single and double gene carriage of the SE resulted in a higher median radiological progression rate compared with absence of the SE, and no statistically significant difference between double and single gene carriage of the SE was observed (single SE versus absence: $3.45 \vee 2.14, \mathrm{p}=0.040$; double $\mathrm{SE}$ versus absence: $4.00 \vee 2.14$, $\mathrm{p}=0.036$; single SE versus double SE: $3.45 \vee 4.00, \mathrm{p}=0.782$; $\mathrm{p}$ values were corrected for multiple comparisons using the Bonferroni procedure) (fig 1).

Levels of RF, anti-pepB antibodies, and anti-CCP2 antibodies correlated weakly but significantly with the radiological progression rates $\left(\mathrm{r}_{\mathrm{s}}=0.249, \mathrm{p}=0.001\right.$; $\mathrm{r}_{\mathrm{s}}=0.180, \mathrm{p}=0.016 ; \mathrm{r}_{\mathrm{s}}=0.268, \mathrm{p}<0.001$, respectively). No significant correlation was found for anti-pepA antibodies $\left(r_{s}=0.127, p=0.089\right)$. To evaluate whether we could define a cut off value for each assay that could differentiate between patients with the greatest erosion (defined as the $25 \%$ highest radiological progression rates) and those with the least (defined as the $75 \%$ lowest radiological progression rates), we performed ROC curve analysis and computed the area under the curve. The anti-CCP2 antibodies gave the highest area under the curve (0.595). However, this value was not sufficiently high to define a cutoff value with acceptable sensitivity and specificity in determining those patients with the most radiologically progressive RA.

As neither the dichotomous nor the continuous approach could be extrapolated for individual patients, we applied a different "clustering" technique to deduce the importance of combinations of parameters that could identify patients with the highest expectancy rate for the $25 \%$ highest radiological progression rate. Only three discrete parameters were considered: RF, anti-CCP2 antibodies (representative for anticitrullinated protein antibodies), and the SE. Eight distinct combinations were sorted spontaneously according to the presence or absence of these three parameters: RF (cut off $\geqslant 150 \mathrm{U} / \mathrm{ml}$ ), the SE and anti-CCP2 antibodies (cut off $\geqslant 42 \mathrm{U} / \mathrm{ml}$ ). As each combination had to contain at least 10 patients for generating a prediction, only four combinations had enough patients to be useful; these are given in table 3 . The other four combinations were not considered for analysis. Table 3 shows that the simultaneous presence of RF, anti-CCP2 antibodies, and the SE is linked to the highest expectancy rate $(40 \%)$ for high radiological progression rates for high radiological progression rates. Table 3 can be divided into three 


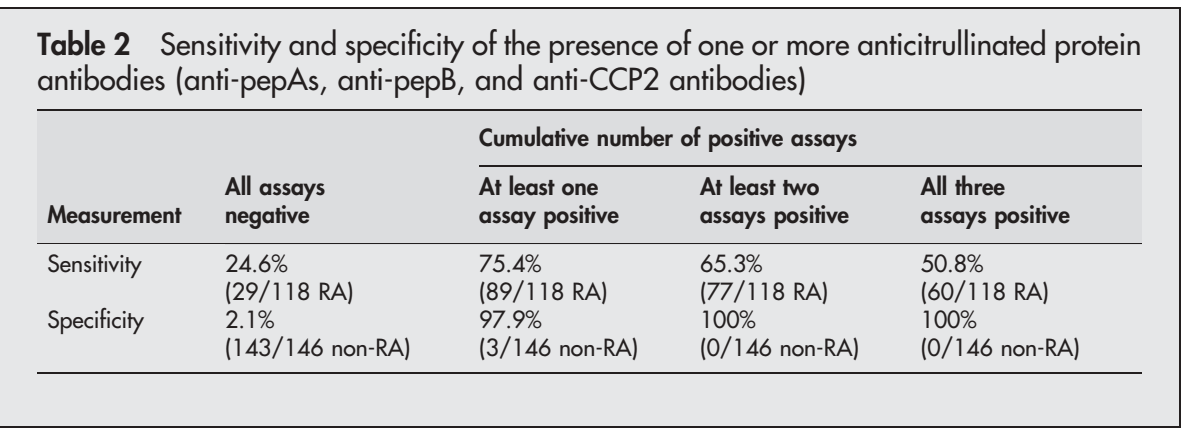

regions: low risk, with an average expectancy rate for high radiological progression rates of only $4.3 \%$; medium risk, with an average expectancy rate of $24.7 \%$; and high risk, with an average expectancy rate for high radiological progression rates of $40 \%$, which is 10 times the expectancy rate of the low risk region in which all parameters are absent (low risk versus medium risk $\mathrm{p}=0.064$; medium risk versus high risk $\mathrm{p}=0.246$, low risk versus high risk $\mathrm{p}=0.006$; $\mathrm{p}$ values were corrected for multiple comparisons using the Bonferroni procedure).

\section{Association of RF and anticitrullinated protein antibodies with the SE in study population 2}

The SE was present in 129/171 (75.4\%) longstanding RA patients; 96/171 (56.1\%) RA patients carried one copy of the SE, and 33/171 (19.3\%) carried two copies. Based on the adapted cut offs, the anticitrullinated protein antibodies, but not RF, were significantly more frequent among those who had a single or double gene carriage of the SE versus those who had no SE (RF 26.4\% $v$ 24.4\%, $\mathrm{p}=0.802$; anti-pepA antibodies $65.9 \% \vee 31.0 \%, \mathrm{p}<0.001$; anti-pepB antibodies:

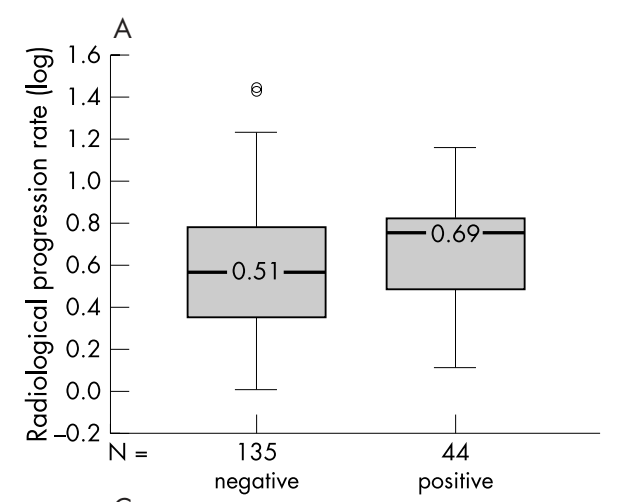

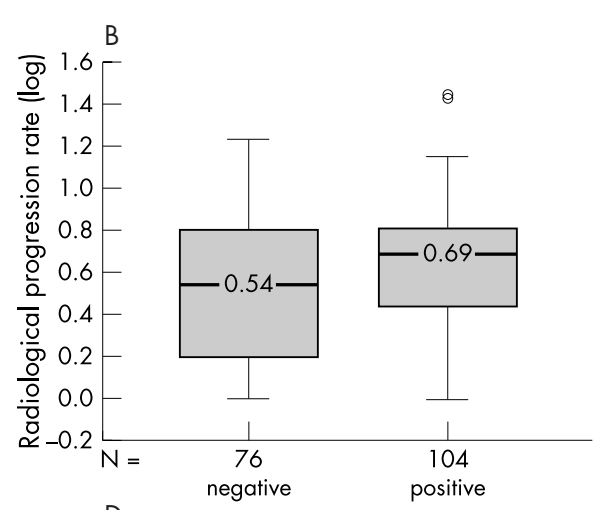

Figure 1 Radiological progression rates according to the autoantibody status (positive or negative) and the shared epitope status (SE) (no, single or double SE). Median radiological progression rates (logarithmic transformation) are indicated. (A) RF $(p=0.043) ;(B)$ anti-peptide $A$ antibodies $(p=0.024)$; $(C)$ anti-peptide $B$ antibodies $(p=0.008)$; (D) anti-CCP2 antibodies $(p=0.001)$; (E) SE. SE, single versus negative: $p=0.040 ; S E$, double versus negative: $p=0.036$; $S E$, single versus double: $p=N S$; $S E$, single or double versus negative: $p=0.009$

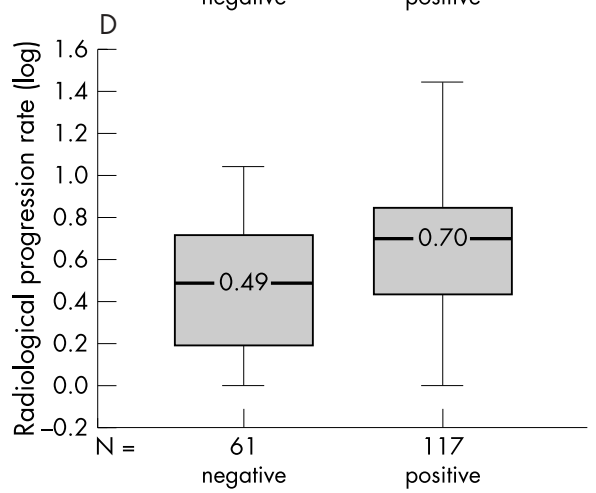


Table 3 Risk for high radiological progression rate based on the combinations of RF, the SE, and anti-CCP2 antibodies

\begin{tabular}{lllll}
\hline $\begin{array}{l}\text { (RF, SE, } \\
\text { anti-CCP2 } \\
\text { antibodies) }\end{array}$ & $\begin{array}{l}\text { No. of } \\
\text { patients }\end{array}$ & \% Low & \% High & $\begin{array}{l}\text { Risk for high } \\
\text { radiological } \\
\text { progression rate }\end{array}$ \\
\hline--- & 23 & 95.7 & 4.3 & Low \\
-+- & 35 & 74.3 & 25.7 & Medium \\
-++ & 59 & 76.3 & 23.7 & Medium \\
+++ & 25 & 60.0 & 40.0 & High \\
\hline
\end{tabular}

+, Parameter present; -, parameter absent. Within each combination (first column), a distinction was made between those patients with a radiological progression rate in the lowest three quartiles (percentage given in column 3), and those patients with a radiological progression rate in the highest quartile (percentage given in column 4).

64.3\% $v$ 28.6\%, $\mathrm{p}<0.001$; anti-CCP2 antibodies: $76.4 \% \quad v$ $33.3 \%, \mathrm{p}<0.001)$.

\section{Association of RF, anticitrullinated protein antibodies and the SE with extra-articular manifestations in study population 2}

During the course of their disease 40 of the 180 patients $(22.2 \%)$ had vasculitis $(n=7)$ or rheumatoid nodules $(n=33)$. Based on the adapted cut offs, RF, but not the anticitrullinated protein antibodies, was significantly more frequent among patients who had extra-articular manifestations compared with those without (RF, $40.0 \% \vee 20.1 \%$, $\mathrm{p}=0.010$; anti-pepA, 65.0\% $\vee 55.7 \%, \mathrm{p}=0.294$; anti-pepB, $62.5 \% \quad v 52.9 \%, \quad \mathrm{p}=0.280$; anti-CCP2, $72.5 \% \quad v \quad 63.8 \%$, $\mathrm{p}=0.306)$. No significant association was found between the SE and the presence of extra-articular manifestations (74.4\% of patients with extra-articular manifestations versus $75.8 \%$ of patients without; $p=0.859$ ). Double gene carriage of the SE was also not significantly correlated with extraarticular manifestations ( $50 \%$ of patients with versus $41.8 \%$ without; $\mathrm{p}=0.528$ ).

\section{DISCUSSION}

In the first part of the present study, we evaluated the diagnostic performances of RF detection and three assays for the detection of anticitrullinated protein antibodies in RA. To our knowledge, this is the first study to validate three different synthetic citrullinated peptides (CCP2, pepA, and pepB) together with RF on the same cohort of patients with inflammatory joint disease. We would like to highlight that we used the recently developed CCP2 peptides, which have replaced the CCPI peptide in the Immunoscan RA assay. It needs to be emphasised that a valid comparison of the diagnostic value of the RA associated antibodies should be performed at an equal specificity level, determined on the same population. Therefore, we performed ROC curve analysis on a consecutive group of patients with inflammatory joint symptoms in order to define cut offs corresponding to a specificity level of at least $98.5 \%$. At this high specificity level, the sensitivities ranged from $12.8 \%$ for RF to $73.7 \%$ for anti-CCP2 antibodies. The sensitivity of RF was significantly lower than the sensitivity of the anticitrullinated protein antibodies. Our findings confirm the data of Suzuki et al, who recently reported the superiority of anticitrullinated protein antibodies to RF in the diagnosis of RA. At a fixed specificity level of $90 \%$, they found significantly higher sensitivities for anti-CCP2 antibodies and anti-filaggrin antibodies than for RF $\left(84.2 \%, 72.5 \%\right.$, and $54.5 \%$ respectively). ${ }^{12}$ In our present study, no final superiority could be found between the three synthetic peptides (pepA, pepB, CCP2). In the current patient population setting and at a specificity level of at least $98.5 \%$,
anti-CCP2 antibodies were more sensitive than anti-pepA antibodies $(p=0.008)$, which were in turn more sensitive than anti-pepB antibodies $(p=0.014)$. A second analysis in a longstanding RA population gave similar sensitivities for anticitrullinated protein antibodies, and confirmed that anticitrullinated protein antibodies have a superior sensitivity compared with RF.

As it has previously been described that not all patients with RA react against the same citrullinated epitopes, ${ }^{2-4} 62122$ we analysed whether combining anticitrullinated protein antibody detection methods could upgrade the sensitivities for RA without lowering the specificity. Of the patients, 75\% showed anticitrullinated protein antibodies in at least one of the assays. However, this maximum sensitivity was not significantly different from the performance of the anti-CCP2 assay alone. Against two or more synthetic citrullinated peptides, $65 \%$ showed simultaneous reactivity, diagnosing RA with certainty (specificity $100 \%$ ). Adding the result of RF testing also could not upgrade the diagnostic performance significantly. In the literature, the complementarity of RF to anticitrullinated protein antibodies is controversial. Some reports suggest that RF and anticitrullinated protein antibodies should be combined to reach optimum diagnostic properties, ${ }^{6} 9102223$ whereas others find only little additional diagnostic value when combining $\mathrm{RF}$ and anticitrullinated protein antibodies. ${ }^{21}$ The discrepancy can be explained by the fact that in the literature a stratification for specificity was not performed, and therefore, the results of different studies are not comparable. Further international discussion is warranted to answer the question of whether anticitrullinated protein antibodies should replace or complement RF in the future, especially as RF constitutes one of the revised ACR criteria for RA.

It is not only important to identify autoantibodies with high diagnostic performances (high sensitivity, specificity, present early in disease); the possible association with radiological evolution is also intriguing. In the second part of the present study, the relationship between antibodies to the three different synthetic citrullinated peptides, RF, the $\mathrm{SE}$, and the radiological progression rate was studied in a cross sectional sample of patients with RA. As the radiological damage is highly dependent on the disease duration, we corrected the Larsen score for disease duration (radiological progression rate) to offer an alternative for a prospective study. Evidence has been given by several study groups that radiographic progression occurs in the majority of patients at a constant rate in the natural course of RA, certainly after a disease duration of at least 2 years (16-18, 22,24 ). As our RA cohort (study population 2) is a longstanding RA population with a median disease duration of 9.0 years (range 4-39), the effect of a more rapid radiological evolution in the early phases of disease will probably have evened out. We observed that dichotomisation based on the diagnostic performances of the RF, the three anticitrullinated protein antibodies, and the SE gave statistically significant differences in the mean radiological progression rates between the parameter positive and parameter negative groups. No significant difference was observed between single and double gene carriage of the SE. These data are comparable with the findings of other groups using a similar approach. ${ }^{14}$ 25-31 However, it needs to be emphasised that the results based on dichotomisation on group level cannot be extrapolated to individual radiological outcome, and are therefore not useful in everyday clinical practice. In order to overcome this problem, we further investigated whether appropriate cut offs could be determined to identify those patients with the most aggressive radiological course. Therefore, ROC curve analysis was applied on the levels of the different autoantibodies. 
However, the obtained areas under the curve were insufficient to retrieve cutoff values with reliable diagnostic performance for the $25 \%$ worst radiological progression rates.

Because we saw a significant difference in mean radiological progression rates on the group level for RF, anticitrullinated protein antibodies, and the SE, we analysed whether combining RF, anti-CCP2 antibodies, and the SE could give more information on the individual level. A statistical clustering technique revealed that combining those parameters supplies more individual identification for the worst radiological progression rate than a single test alone. The presence of RF, the SE, and anti-CCP2 antibodies yielded a 10 times higher average expectancy rate for a high radiological progression rate compared with the absence of the three parameters. Vencovsky et al demonstrated recently that the combined occurrence of RF and anti-CCP antibodies is highly predictive for early erosions and more progressive disease. ${ }^{31}$ Other previous studies have shown an additional prognostic value for radiological outcome when combining RF with the SE. ${ }^{28}{ }^{29}$ However, until now, no data were available concerning the triple combination including antiCCP2 antibodies accounting for anticitrullinated protein antibodies. ${ }^{25}$

In the third part of the present study, we evaluated the relationship between the RA associated antibodies, the SE, and the presence of vasculitis and/or rheumatoid nodules. The generally accepted positive relation of RF with extraarticular manifestations was confirmed in the longstanding RA population. ${ }^{32}$ The low frequency of RF found in the group of patients with extra-articular manifestations can be ascribed to the high cutoff point used for RF positivity. In contrast, no association between antibodies to synthetic citrullinated peptides and extra-articular manifestations was observed. These findings are congruent with Bas et al, who previously described the absence of association with antikeratin antibodies. ${ }^{26}$ Furthermore, we could not demonstrate a relationship between the SE (single or double gene carriage) and the presence of extra-articular manifestations. The literature concerning the association of the SE with rheumatoid nodules and/or vasculitis remains controversial (reviewed by Gorman et $a^{l^{33}}$ ). The findings in our present study could add support to the existing evidence that RF and anticitrullinated protein antibodies are two separate autoantibody systems: (a) we observed a discrepant association of $\mathrm{RF}$ and anticitrullinated protein antibodies with extraarticular manifestations, and $(b)$ we found a discrepant relationship between RF and anticitrullinated protein antibodies with the presence of the SE.

Considering the link between anticitrullinated protein antibodies and the SE, Hill et al recently demonstrated that the presence of citrulline within the HLA binding peptide enhances the peptide-MHC affinity and leads to the activation of CD4+ $\mathrm{T}$ cells in HLA-DRBl 0401 transgenic mice during presentation of citrullinated antigens. ${ }^{34}$ It might thus be speculated that the citrullination status of a given protein may modulate the immune response against that antigen.

In conclusion, a valid comparison showed that assays based on synthetic citrullinated peptides (pepA, pepB, or CCP2) are superior to RF for the detection of RA. The presence of RA associated antibodies and/or the SE is indicative for a poorer radiological outcome. Extra-articular manifestations are associated with RF but not with anticitrullinated protein antibodies or SE.

\section{ACKNOWLEDGEMENTS}

The authors wish to thank J Discart, A Heirwegh, H Lootens and S De Spiegeleer for their excellent technical assistance, and H Pottel for his statistical advice.

\section{Authors' affiliations}

L De Rycke, I Peene, I E A Hoffman, E Kruithof, H Mielants, E M Veys, F De Keyser, Department of Rheumatology, Ghent University Hospital, Ghent, Belgium

A Union, L Meheus, K Lebeer, Innogenetics NV, Ghent, Belgium

C Vincent, G Serre, Institut National de la Santé et de la Recherche Medicale (INSERM CJF 96-02, IFR30), Purpan School of Medicine, University of Toulouse III, Toulouse, France

B Wyns, L Boullart, Department of Electrical Energy, Systems, and Automation, Ghent University, Ghent, Belgium

This work was supported by a grant from the 'Vlaams instituut voor de bevordering van het wetenschappelijk-technologisch onderzoek in de industrie' (IWT/SB/11127) and a research grant from the 'Biizonder Onderzoeksfonds' Ghent University.

The first two authors contributed equally to this manuscript.

\section{REFERENCES}

1 Arnett FC, Edworthy SM, Bloch DA McShane DJ, Fries JF, Cooper NS, et al. The American Rheumatism Association 1987 revised criteria for the classification of rheumatoid arthritis. Arthritis Rheum 1988;31:315-24.

2 Vincent C, De Keyser F, Masson-Bessière C, Sebbag M, Veys EM, Serre G. Antiperinuclear factor compared with the so called antikeratin antibodies and antibodies to human epidermal filaggrin, in the diagnosis of arthritides. Ann Rheum Dis 1999:58:42-8.

3 Vincent C, Simon M, Sebbag M, Girbal-Neuhauser E, Durieux JJ, Cantagrel A, et al. Immunoblotting detection of autoantibodies to human epidermis filaggrin: a new diagnostic test for rheumatoid arthritis. J Rheumatol 1998;25:838-46.

4 Nogueira L, Sebbag M, Vincent C, Arnaud M, Fournie B, Cantagrel A, et al. Performance of two ELISAs for antifilaggrin autoantibodies, using either affinity purified or deiminated recombinant human filaggrin, in the diagnosis of rheumatoid arthritis. Ann Rheum Dis 2001;60:882-7.

5 Vincent C, Nogueira L, Sebbag M, Chapuy-Regaud S, Arnaud M, Letourneur $\mathrm{O}$, et al. Detection of antibodies to deiminated recombinant rat filaggrin by enzyme-linked immunosorbent assay. Arthritis Rheum 2002;46:2051-8

6 Union A, Meheus L, Humbel R, Conrad K, Steiner G, Moereels H, et al. Identification of citrullinated rheumatoid arthritis-specific epitopes in natural filaggrin relevant for antifilaggrin autoantibody detection by line immunoassay. Arthritis Rheum 2002;46:1185-95.

7 Schellekens GA, de Jong BA, van den Hoogen FH, van de Putte LB, van Venrooii WJ. Citrulline is an essential constituent of antigenic determinants recognized by rheumatoid arthritis-specific autoantibodies. J Clin Invest 1998;101:273-81

8 Girbal-Neuhauser E, Durieux J-J, Arnaud M, Dalbon P, Sebbag M, Vincent C, et al. The epitopes targeted by the rheumatoid arthritis-associated antifilaggrin autoantibodies are posttranslationally generated on various sites of (pro)filaggrin by deimination of arginine residues. J Immunol 1999; 162:585-94.

9 Schellekens GA, Visser $\mathrm{H}$, de Jong BAW, van den Hoogen FHJ, Hazes JMW, Breedveld FC, et al. The diagnostic properties of rheumatoid arthritis antibodies recognizing a cyclic citrullinated peptide. Arthritis Rheum 2000;43:155-63.

10 Bizarro N, Mazzanti G, Tonutti E, Villalta D, Tozolli R. Diagnostic accuracy of the anti-citrulline antibody assay for rheumatoid arthritis. Clin Chem 2001;47:1089-93

11 Vossenaar ER, van Venrooij WJ, Pruijn CJM. Anti-CCP antibodies in (early) rheumatoid arthritis. In: Conrad K, Fritzler M, Meurer M, Sack U, Shoenfeld Y, eds. From proteomics to molecular epidemiology: relevance of autoantibodies: report on the 6th Dresden symposium held in Dresden, September 4-7 2002:454-62.

12 Suzuki K, Sawada T, Murakami A, Matsui T, Tohma S, Nakazono K, et al. Yamamoto K. High diagnostic performance of ELISA detection of antibodies to citrullinated antigens in rheumatoid arthritis. Scand J Rheumatol 2003;32:197-204

13 Harrison B, Thomson W, Symmons D, Ollier B, Wiles N, Payton T, et al. The influence of HLA-DRB 1 alleles and rheumatoid factor on disease outcome in an inception cohort of patients with early inflammatory arthritis. Arthritis Rheum 1999:42:2174-83.

14 Moreno I, Valenzuela A, Garcia A, Yelamos J, Sanchez B, Hernanz W. Association of the shared epitope with radiological severity of rheumatoid arthritis. J Rheumatol 1996;23:6-9.

15 Paimela L, Leirisalo-Repo M, Helve T, Koskimies S. The prognostic value of HLA DR4 and B27 antigens in early rheumatoid arthritis. Scand J Rheumatol 1993;22:220-4.

16 Hulsmans HMJ, Jacobs JWG, Van Der Heijde D, Van Albada-Kuipers GA, Schenk Y, Biilsma JWJ. The course of radiological damage during the first six years of rheumatoid arthritis. Arthritis Rheum 2000;43:1927-40.

17 Sharp JT, Wolfe F, Mitchell DM, Bloch DA. The progression of erosion and joint space narrowing scores in rheumatoid arthritis during the first twenty-five years of disease. Arthritis Rheum 1991;34:660-8.

18 Wolfe F, Sharp JT. Radiographic outcome of recent-onset rheumatoid arthritis. Arthritis Rheum 1998;41:1571-82.

19 Lipsky PE, van der Heijde DM, St Clair EW, Furst DE, Breedveld FC, Kalden JR, et al. Infliximab and methotrexate in the treatment of rheumatoid arthritis. 
Anti-tumor necrosis factor trial in rheumatoid arthritis with concomitant therapy study group. N Engl J Med 2000;343:1594-602.

20 Cohen S, Cannon GW, Schiff M, Weaver A, Fox R, Olsen N, et al. Two-year, blinded, randomized, controlled trial of treatment of active rheumatoid arthritis with leflunomide compared with methotrexate. Utilization of Leflunomide in the Treatment of Rheumatoid Arthritis Trial Investigator Group. Arthritis Rheum 2001;44:1984-92.

21 Goldbach-Mansky R, Lee J, McCoy A, Hoxworth J, Yarbora C, Smolen JS, et al. Rheumatoid arthritis associated autoantibodies in patients with synovitis of recent onset. Arthritis Res 2000;2:236-43.

22 Van Jaarsveld CHM, ter Borg EJ, Jacobs JWG, Schellekens GA, GmeligMeyling FHJ, van Booma-Frankfort $C$, et al. The prognostic value of the antiperinuclear factor, anti-citrullinated peptide antibodies and rheumatoid factor in early rheumatoid arthritis. Clin Exp Rheum 1999;17:689-97.

23 Jansen ALMA, van der Horst-Bruinsma IE, van Schaardenburg D, van de Stadt RJ, de Koning MHMT, Dijkmans BAC. Rheumatoid factor and antibodies to cyclic citrullinated peptide differentiate rheumatoid arthritis from undifferentiated polyarthritis in patients with early arthritis. J Rheumatol 2002;29:2074-6.

24 Plant MJ, Jones PW, Saklatvala J, Ollier WER, Dawes PT. Patterns of radiological progression in early rheumatoid arthritis: results of an 8 year prospective study. J Rheumatol 1998;25:417-26.

25 Kroot EJ, De Jong BAW, Van Leeuwen MA, Swinkels H, Van den Hoogen FHJ, van't Hof $M$, et al. The prognostic value of anti-cyclic citrullinated peptide antibody in patients with recent onset rheumatoid arthritis. Arthritis Rheum 2000;43:1831-5

26 Bas S, Perneger TV, Mikhnevitch E, Seitz M, Tiercy JM, Roux-Lombard P, et al. Associations of rheumatoid factors and anti-filaggrin antibodies with severity of erosions in rheumatoid arthritis. Rheumatology 2000;39:1082-8.
27 Aho K, Palosuo T, Lukka M, Kurki P, Isomaki H, Kautiainen $\mathrm{H}$, et al. Anti-filaggrin antibodies in recent onset arthritis. Scand $J$ Rheumatol 1999;28:113-16.

28 Kaltenhäuser S, Wagner U, Schuster E, Wassmuth R, Arnold S, Seidel W, et al. Immunogenetic markers and seropositivity predict radiological progression in early rheumatoid arthritis independent of disease activity. $J$ Rheumatol $2001 ; 28: 735-44$.

29 Mattey DL, Hassell AB, Dawes PT, Cheung NT, Poulton KV, Thomson W, et al. Independent association of rheumatoid factor and the HLA-DR B1 Shared epitope with radiographic outcome in rheumatoid arthritis. Arthritis Rheum 2001;44:1529-33.

30 Meyer O, Labarre C, Dougados M, Goupille Ph, Cantagrel A, Dubois A, et al. Anticitrullinated protein/peptide antibody assays in early rheumatoid arthritis for predicting five year radiographic damage. Ann Rheum Dis 2003;62:120-6.

31 Vencovsky J, Machacek S, Sedova L, Kafkova J, Gatterova J, Pesakova V, Ruzickova S. Autoantibodies can be prognostic markers of an erosive disease in early rheumatoid arthritis. Ann Rheum Dis 2003;62:427-30

32 Smolen JS. Autoantibodies in rheumatoid arthritis. In: Van Venrooij WJ, Maini RN, eds. Manual of biological markers of disease. Dordrecht, The Netherlands: Kluwer Academic Publishers, 1996;C1:1, 1-18.

33 Gorman JD, Criswell LA. The shared epitope and severity of rheumatoid arthritis. Rheum Dis Clin North Am 2002;28:59-78.

34 Hill JA, Southwood S, Sette A, Jevnikar AM, Bell DA, Cairins E. Cutting edge: the conversion of arginine to citrulline allows for a high affinity peptide interaction with the rheumatoid arthritis-associated HLA-DRB 1 *0401 MHC class II molecule. J Immunol 2003;171:538-41. 